\title{
Students from Garcia Summer Program present research at MRS virtual meeting
}

\author{
By Lori A. Wilson
}

In addition to entering national competitions, students are encouraged to publish in refereed scientific journals, present their results at national conferences, network with each other, and build long-standing relationships.

$\mathrm{D}^{\mathrm{s}}$ ing the 2020 Materials Research Society (MRS) Virtual Spring and Fall Meeting, students from the Garcia Summer Program at Stony Brook University, The State University of New York, had an opportunity to present on their topics of research that ranged in scope from "Molecular Dynamics Prediction of SARS-CoV-2 Spike Glycoproteins at Varying Temperature Using Machine Learning Models" to "Effects of Shear Stress and Confinement on HUVECs." Fourteen abstracts were presented as posters, and three oral presentations were given in the special symposium on Materials Approaches for Tackling COVID-19.

The MRS Meeting submissions are reviewed by top scientists, and a decision is made on whether to accept the presentations based on the quality of the project. To have symposia accepted from dozens of students as well as

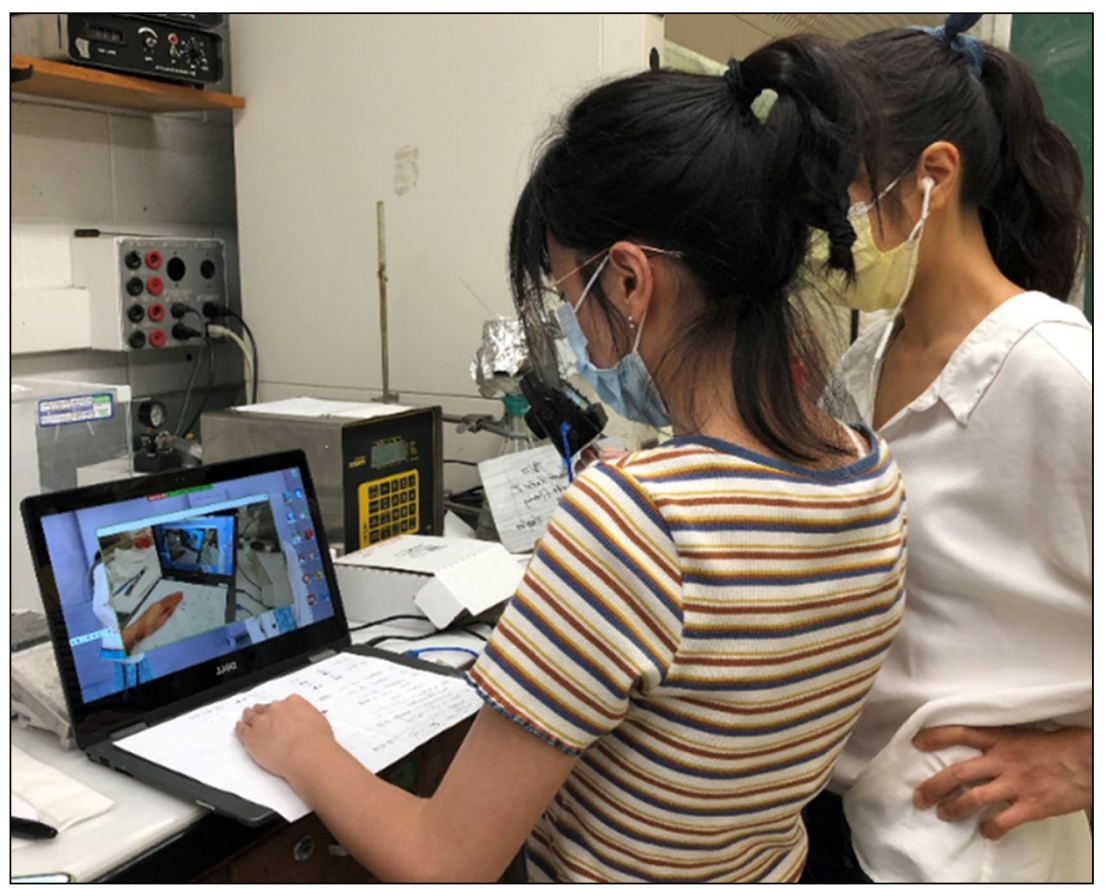

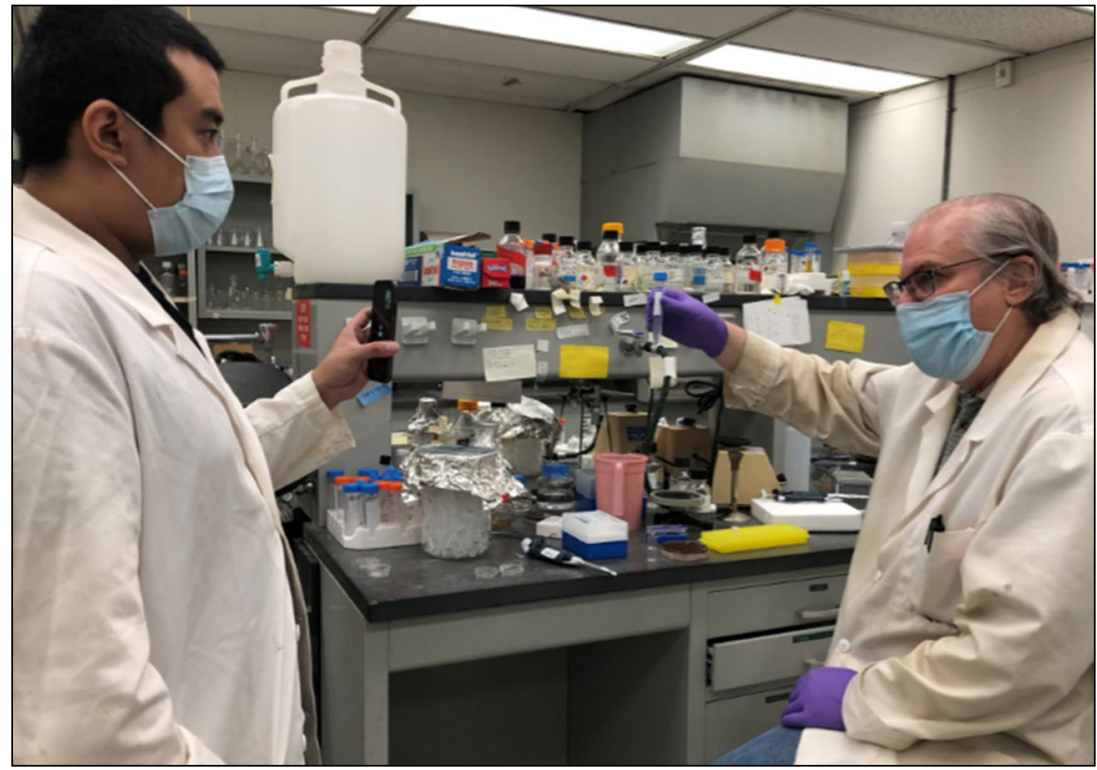

opportunities for them to present their findings is a great honor and special achievement. Scholar Program for high school students, which offers the opportunity for high school teachers and students in grades 9-12 to perform research on the forefront of polymer science and technology, together with the Garcia faculty and staff. The goal of the Garcia pre-college program is to convey polymer materials research to students and their teachers and to suggest possible career options.

Students work as part of focused research teams and are taught to make original contributions of interest to the scientific community. In addition to entering national competitions, students are encouraged to publish in refereed scientific journals, present their results at national conferences, network with each other, and build long-standing relationships. The seven-week summer program combines formal instruction with independent research that allows students to design original research projects with guidance from Garcia Center 


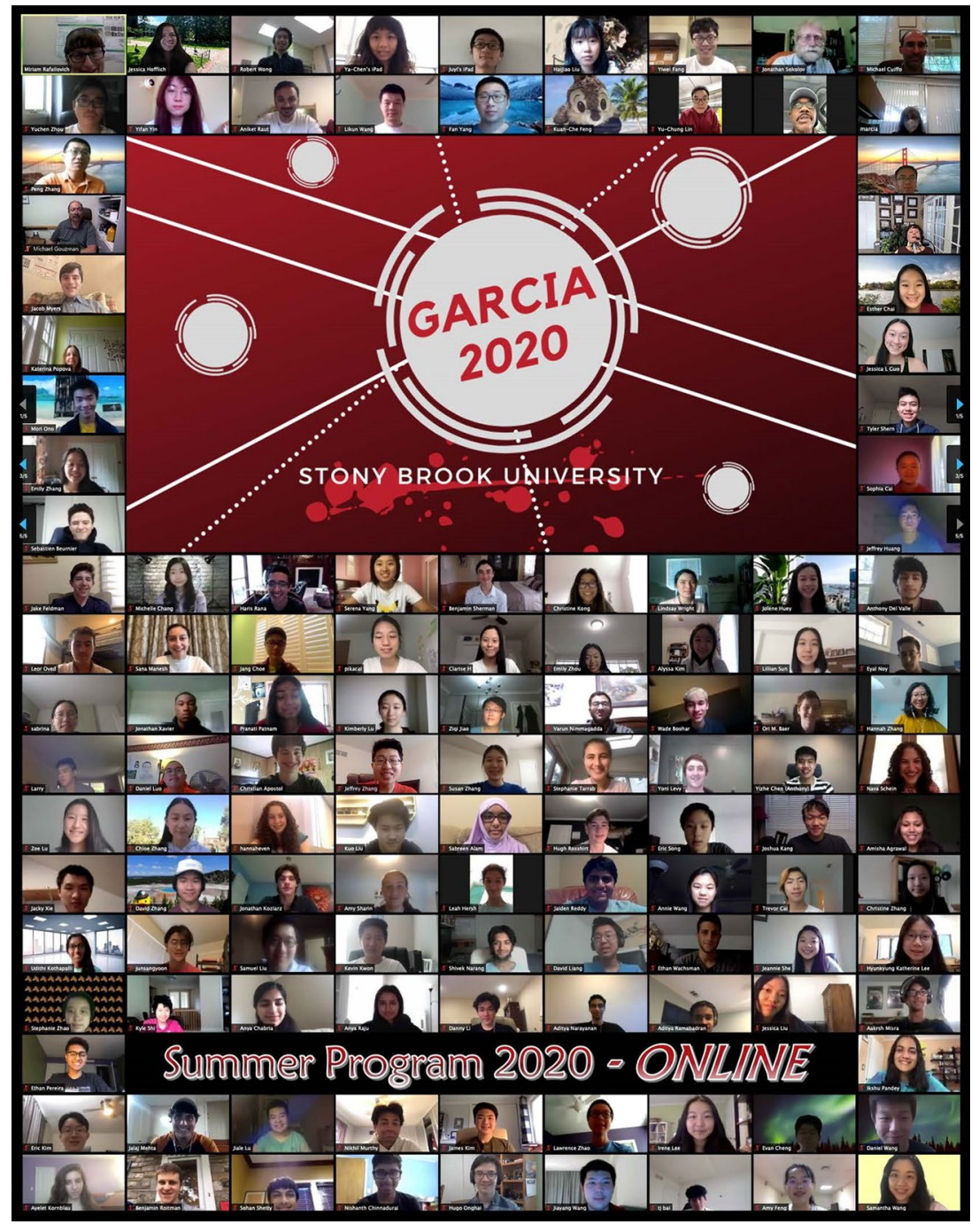

faculty, students, and staff. Students can then continue in the Mentor Program, which allows them to plan a research schedule with a faculty mentor throughout the year. Almost 500 students have participated in the program since its inception in 1998. A recent survey of past graduates ${ }^{1}$ found that when comparing students who had attended the program with a control group from similar high schools and backgrounds, a significantly higher fraction majored in STEM fields, pursued careers in STEM disciplines, and found the experience to strategically influence their job performance. Furthermore, the students reported that the friendships they made have lasted for years and formed a support network that has grown with them.

This past year's summer program was especially challenging due to the pandemic, which caused all aspects of the hands-on program to go virtual. Stony Brook staff wore GoPro cameras and livestreamed the lab work. Participants were involved from many states and countries, presenting additional challenges. Instead of participating in baseball games, canoe trips, and expeditions to New York City, this year's cohort bonded online via Yoga from Australia, participated in a synchronous digital orchestra, and engaged in a video competition for teaching science to the community.

Miriam Rafailovich, a materials engineering researcher and a distinguished professor of engineering, has directed the Garcia program for 25 years. Rafailovich has provided the opportunity for involvement in cuttingedge science research for more than 2000 high school students. She is not only the initiator and organizer, but also provides the energy, motivation, and entire substance of this extraordinary program.

Rebecca Isseroff, a chemistry and science research teacher at Lawrence High School and a science research teacher at HAFTR, also plays a large role in the program and development of the students. Isseroff's efforts on behalf of the integration of science with education has received many accolades, including those from the American Chemical Society (ACS) and most recently from the National Academy of Inventors. Working together with Marla Boots, senior technical program administrator for MRS, Isseroff helped organize the opportunity for high school students to participate in national professional conferences (e.g., ACS, APS, and MRS), where they can present their work to professionals in their discipline. Isseroff works in a Title I school district, where the family income for the majority of students is below the national poverty level. As such, she has sponsored students who were the first in their families to attend a higher level of education and even graduate from high school. For these students, the experience she has enabled has not only guided them along a career path, but has literally transformed their and their families' lives as well.

"My research project that was presented at the MRS Virtual Meeting involved the novel development of an innovative liquid embolic agent therapy for brain aneurysms," said Tyler Shern, a high school senior who participates in the Garcia Program at Stony Brook University. "My goal was to develop a cost-effective hydrogel that involves short procedure times, generates a porous scaffold that dynamically conforms to the aneurysm, accelerates the body's natural healing mechanisms by promoting cellular organization and endothelialization, and is biodegradable (leaving no residual signs of treatment). As I continue working on engineering this device as part of the upcoming summer's Garcia program, I'm optimistic about improving treatments for brain aneurysm patients worldwide. 
"Even though the program was held virtually this past summer, I was able to form lasting connections with passionate students with similar interests as myself across the country while collaborating on this ambitious research project. The extraordinary experience in computational analysis and biomaterials research will definitely prove useful as I enter college and pursue further research projects," said Shern. "The MRS Meeting was my first experience presenting research at a professional conference. It definitely was an enlightening experience to present alongside thousands of other materials scientists from across the world, especially as a high school student."

Many of the high school students who presented at the MRS virtual conference said it allowed them to improve their presentation skills and scientific writing abilities and increased their desire to conduct, present, and communicate research later in college. They also intend to participate in future MRS meetings.

Jake Dylan Feldman found the Garcia Center for Polymers at Engineered Interfaces to be an extremely rewarding experience. "I was ensconced in a community of dedicated and intelligent peers and instructed by world-renowned faculty. I listened to daily lectures by professors located across the globe from places as far away as Israel and Korea. I honed my research skills and learned about cutting-edge topics, such as bioprinting skin, flame retardant materials, and regenerative medicine. Additionally, I worked alongside peers throughout the United States and foreign countries and learned about their unique lifestyles."

Emily Zhou, a high school junior at The Harker School in California, said that even amid the pandemic, the mentors were able to create an engaging and research-intensive environment. "Not only was I able to immerse myself in fun, complex research projects, I made long-lasting friendships. My teammates and mentors provided a great deal of support while participating in competitions and presenting at professional conferences, such as MRS. Not only was I given the opportunity to share our team's research at live sessions, processing questions from other professional researchers via Zoom, but I was able to listen in on many interesting research presentations that piqued my interest in the biomaterials realm. I became more confident in myself while presenting to an audience of distinguished researchers, and I'll carry this same tenacious mindset to future conferences."

Pranati Patnam, a junior at Herricks High School in New York, said the Garcia Program was her favorite part of the summer. "Whenever understanding advanced materials got tough, my teammates assisted me. It was more of a collaboration rather than a competition. It forces you to come out of your comfort zone and do things that are extraordinary."

Even though many activities have been and remain remote, the Garcia Program participants have been able to gather with other students in their geographical areas for hikes and other small outdoor gatherings to build on their relationships and comradery.

The mentorship in the Garcia Program is personal and supportive of individual students, ensuring each student's engagement and understanding of his or her project. This type of learning environment has a well-studied, positive influence on student academic performance and achievement, ${ }^{2}$ and continues to provide the right environment for attaining outstanding academic goals.

"I'm really glad I was able to participate in the Garcia Program. It broke the academic bubble of classrooms and textbooks and showed me what was going on, scientifically, in the real world. These concepts can be linked to real-world applications that will directly impact my life," said Serena Yang.

\section{References}

1. J. Budassi, M. Rafailovich, The effect of university research apprenticeships for high school students on science, math, engineering, and technology learning and the pursuit of science, math, engineering, and technology degrees and careers. MRS Commun. 8(2), 387 (2018). https:// doi.org/10.1557/mrc.2018.92

2. A.M. Klem, J.P. Connell, J. Sch. Health 74(7), 262 (2004)

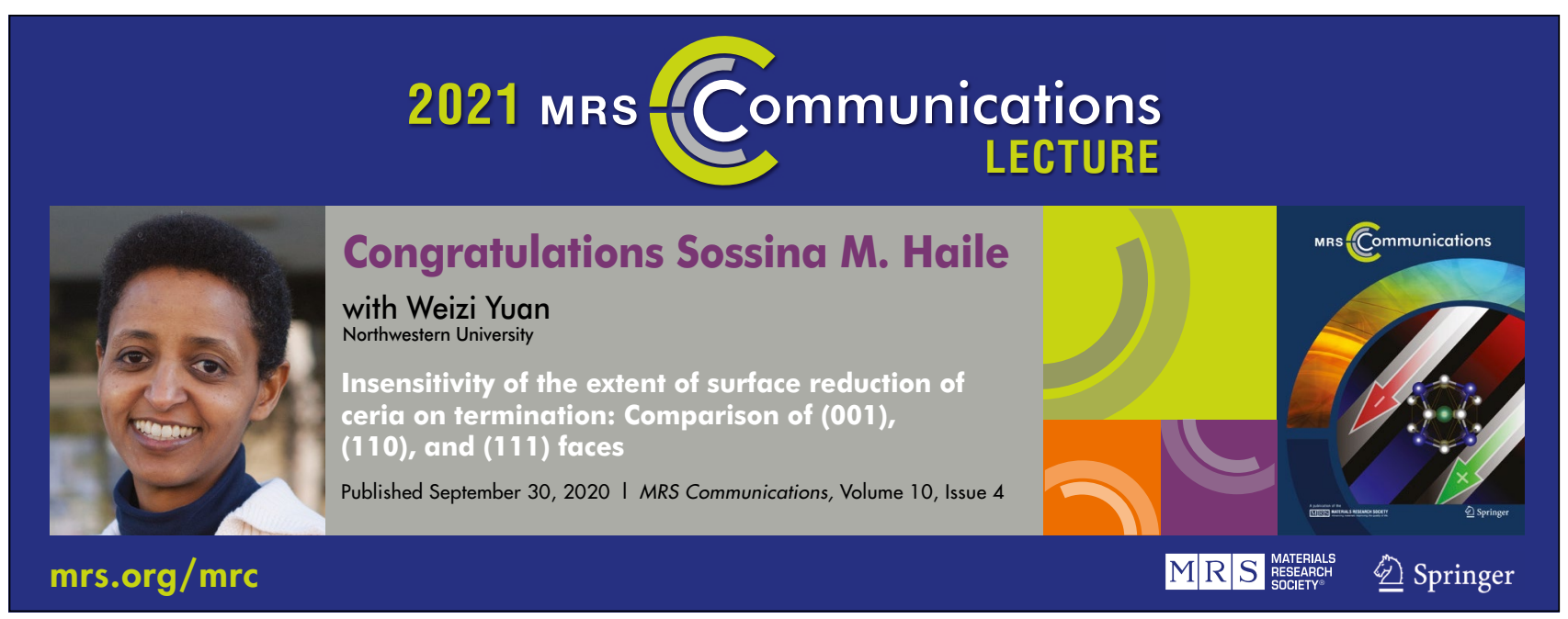

